\title{
Vicarious trauma: The psychological impact of working with survivors of trauma for South African psychologists
}

\author{
Xin-Cheng Sui and Anita Padmanabhanunni
}

\begin{abstract}
Traumatic events are highly prevalent in South African society and psychologists who work with survivors of trauma have been identified as particularly at risk of being adversely affected by their work, and experiencing vicarious trauma. This study aimed to explore the experiences of a group of South African psychologists who work predominantly with trauma survivors. Individual semi-structured interviews were conducted with six psychologists (females $=67 \%$ ). The predominant type of trauma encountered by participants in clinical practice was interpersonal trauma in the form of physical and sexual abuse (83\%). Data were analysed using thematic analysis. All participants reported symptoms of vicarious trauma including disruption in cognitive schemas, symptoms characteristic of post-traumatic stress disorder, and somatic symptoms. Participants also reported vicarious post-traumatic growth including an enhanced sense of interpersonal connectedness and positive changes in their philosophy of life and self-perceptions. The findings serve to sensitise psychologists to the impact of working with trauma survivors so as to enhance the efficiency of psychological service delivery to traumatised populations.
\end{abstract}

\section{Introduction}

Trauma is deeply embedded in South African society, with findings from nationally representative surveys (Kaminer, Grimsrud, Myer, Stein, \& Williams, 2008; Atwoli et al ., 2013) indicating that over $70 \%$ of the country's population has been exposed to at least one traumatic event. The most common forms of trauma include physical abuse by an intimate partner, sexual violence, miscellaneous criminal assaults (e.g. armed robbery) and witnessing someone getting seriously harmed (Atwoli et al ., 2013). The impact of exposure to trauma can be far reaching because of its ability to disrupt or shatter the assumptive world (i.e. cognitive schemas or core beliefs through which people interpret their experiences and make meaning) (Janoff-Bulman, 1985; Herman, 1992). People construct their realities through the development of cognitive schemas. These schemas include beliefs, assumptions and expectations of oneself, other people and the world, and are used to interpret events and make sense of experiences. Typically, people believe that they are worthwhile, have personal control over their lives, that the world is relatively fair and just, and that bad things do not happen to good people. Traumatic events tend to disrupt these assumptions and raise questions about the meaning and purpose of life, the benevolence 
of others and the controllability and fairness of the world (Janoff-Bulman, 1985). This disruption can lead to the modification of the belief system in either a negative way, which can produce psychological distress and lead to post-traumatic stress disorder (PTSD), or in a positive way that leads to transformation and growth (McCann \& Pearlman, 1990).

\section{Post-traumatic stress disorder: symptoms}

PTSD is the most common psychological response to trauma and arises from difficulties reconciling the traumatic event with pre-existing cognitive schemas (Ehlers \& Clark, 2000). The symptoms of PTSD include: intrusive re-experiencing of the traumatic event in the form of nightmares, flashbacks and sensory impressions; cognitive and behavioural attempts to avoid reminders (e .g . suppressing thoughts and memories and avoiding situations that serve as reminders of what happened); negative alteration in cognition and mood (e.g. constricted affect and persistent negative trauma related emotions or beliefs); and symptoms of alterations in arousal and reactivity (e .g . exaggerated startle responses and constant hypervigilance for any signs of danger) (American Psychological Association [APA], 2013) . Recovery from trauma does not mean returning to previously held assumptions but establishing an adaptive assumptive world that integrates the traumatic experience. This involves recognition of vulnerability as well as awareness of strength and self- resilience (Padmanabhanunni \& Edwards, 2015).

\section{Treating trauma survivors}

When providing psychotherapy, psychologists are expected to empathically engage with clients, to have the ability to manage and contain painful emotions evoked, and to be highly sensitive to the emotional needs of those that they work with (Edwards, 2009). When working with trauma survivors, this empathic engagement includes listening to graphic descriptions of traumatic events such as rape, childhood sexual abuse and intimate partner violence, and bearing witness to the human capacity for cruelty as well as the pain and suffering engendered by brutal acts. Just as traumatic events have the potential to shatter the survivor's positive assumptions about themselves, others and the world, exposure to the client's trauma narrative can also impact on the therapist's cognitive schemas. This includes their sense of trust in other people and assumptions about safety (McCann \& Pearlman, 1990). In the literature, this impact of working with trauma on professionals has been interchangeably termed vicarious trauma (McCann \& Pearlman, 1990), compassion fatigue (Figley, 1999), secondary traumatic stress (Figley, 1995) and burnout (Maslach, 1982). For the purposes of this paper, the conceptual framework of vicarious trauma (McCann \& Pearlman, 1990; Pearlman \& Caringi, 2009) is used as it was designed to capture the psychological consequences of working with trauma survivors.

\section{Vicarious trauma: symptoms and recovery}

Vicarious trauma leads to 'permanent transformation in the inner experience of the therapist ${ }^{1}$ that comes about as a result of empathic engagement with clients' trauma material' (Pearlman \& Sakvitne, 1995, p . 31). It involves a transformation in the therapist's enduring ways of experiencing the self, others and the world as a result of engaging empathically with a client's trauma material. It entails profound and 
permanent changes in the way a therapist's thinks, feels and behaves in relation to others and themselves. Moreover, subclinical symptoms of PTSD including intrusive reexperiencing of aspects of the client's trauma, alterations in cognition and affect, and physiological hyperarousal all form part of the phenomenology of vicarious trauma (McCann \& Pearlman, 1990). Other symptoms of vicarious trauma include emotional symptoms such as heightened levels of anxiety, depressed mood and discouragement, and behavioural symptoms such as limited desire for intimacy in close relationships, or increased substance use (McCann \& Pearlman, 1990; Rich, 1997). Unaddressed vicarious trauma can lead to a loss of efficiency in treatment delivery and diminished job satisfaction (Pearlman \& Saakvitne, 1995).

There has been increasing recognition of the potential for personal growth as a result of working with survivors of trauma (Arnold, Calhoun, Tedeschi, \& Cann, 2005). This potential for growth and transformation as a result of exposure to trauma has been framed within the broader concept of post-traumatic growth (Calhoun \& Tedeschi, 2006). Posttraumatic growth is defined as significant psychological growth following major life crises or traumas (Tedeschi \& Calhoun, 1996). In the same way survivors of trauma may experience positive growth as a result of their experiences, therapists who work with survivors have been found to experience similar transformations known as vicarious posttraumatic growth as a result of vicarious exposure to trauma (Arnold et al., 2005). Areas of growth can include positive changes in self-perception, changes in interpersonal relationships and changes in life philosophy (Tedeschi \& Calhoun, 1996).

In South Africa, few studies have investigated the psychological impact on therapists who work with trauma survivors. Existing studies in this area have conceptualised the impact of working with challenging populations as 'burnout' or 'secondary traumatic stress' and have been mostly quantitative in nature, focusing on prevalence rates (e.g. Jordaan, Spangenberg, Watson, \& Fouchè, 2007; Ludick, Alexander, \& Carmichael, 2007; MacRitchie \& Leibowitz, 2010; Du Plessis, Visagie, \& Mji, 2014). The current study is distinctive in that it provides qualitative insights into the experiences of a group of psychologists who work with trauma survivors. This type of information would be beneficial in sensitising psychologists to the impact of such work and highlight the content areas that need to be included in training programmes for psychologists who intend to work in the area of trauma.

\section{Goals of the study}

The current study sought to explore the lived experiences of a group of South African psychologists who work with trauma survivors. The specific questions for study were:

1. How do psychologists experience working with trauma survivors?

2. What are the psychological consequences of working with trauma?

\section{Method}

\section{Research design}

The study used a descriptive phenomenological approach so as to obtain insights into the lived experiences of the participants. The phenomenological approach offers a rich and 
textured description of experiences through the qualitative investigation of the human world (Finlay, 2009). The lived experiences as presented in individuals' consciousnesses are the basis for uncovering the essence of a phenomenon (McPhail, 1995). This study attempted to bring out the vital features of participants' experiences to understand their constructed meaning of working with survivors of trauma.

\section{Participants and setting}

Participants were a purposive sample of six practising psychologists recruited from open access websites (e.g.therapydirectory .co.za) where psychologists advertise their practice (see Table 1 on sample characteristics). The first author compiled a list of psychologists who indicated on these websites that they worked predominantly with trauma and PTSD. These practitioners were contacted via email and invited to participate.

Table 1: Sample characteristics

\begin{tabular}{|c|c|c|}
\hline Name & Registration category & Major trauma practice area \\
\hline Tammy & Clinical psychologist & $\begin{array}{l}\text { sexual abuse; bereavement; complication of PTSD from emotional and verbal abuse; } \\
\text { witnessing trauma }\end{array}$ \\
\hline Wendy & Counselling psychologist & $\begin{array}{l}\text { sexual abuse; bereavement; separation; transferring; loss of possession; physical abuse; } \\
\text { emotional abuse; witnessing trauma }\end{array}$ \\
\hline Jennifer & Clinical psychologist & sexual trauma \\
\hline Eugene & Clinical psychologist & political violence \\
\hline Monica & Clinical psychologist & terminal illness; bereavement; motor vehicle accidents; physical and emotional abuse \\
\hline Kevin & Counselling psychologist & hijackings, break-ins, domestic violence \\
\hline
\end{tabular}

Six psychologists responded (four female and two male participants). They were registered as either clinical or counselling psychologists with the Health Professions Council of South Africa (HPCSA) and had at least three years of experience in working with trauma survivors. Respondents worked in private practice or community and public health settings (e .g . non-governmental organisations). The types of traumatic events that they encountered among their client population predominantly involved interpersonal traumas in the form of sexual, physical and emotional abuse as well as bereavement and exposure to political violence. The following pseudonyms were used for participants: Tammy, Eugene, Jennifer, Monica, Wendy and Kevin .

\section{Data collection}

Each participant took part in a 60-minute semi-structured interview conducted by the first author. Interview questions focused on the types of traumatic events participants encountered among their client population, the challenges they experienced in working with this population, and their reactions to trauma work. After each interview, the first author made notes on her experience of the interview and her reflections including emerging concepts and themes. Interviews were audio recorded and transcribed verbatim. Credibility of the data was established through 'member checking' . Participants were provided with the transcript of their interview to verify that the information contained in the transcript was representative of their perspective. Additionally, an independent assessor evaluated 
the transcripts against the audio recordings and the identified themes. No distortions were reported.

\section{Ethical considerations}

Ethical approval for the study was given by the University of the Western Cape through the Department of Psychology. Participants gave written informed consent and their confidentiality and anonymity were ensured. Pseudonyms were used in all reports to protect their identities.

\section{Data analysis}

The data was analysed using thematic analysis (Braun \& Clarke, 2006). There were two phases to data analysis. The first phase involved compiling a case narrative for each of the participants that summarised the nature of their trauma work, their psychological responses to such work including alterations in cognitions, emotions and beliefs, as well as their interpretations of the impact of such work on their professional and personal lives. For the second phase, the interviews were subjected to thematic analysis (Braun \& Clark, 2006) . Following several readings of the text, data were initially coded and collated . Subsequently, connections between the codes were examined to identify emerging themes (e .g. 'disruption in cognitive schema', 'persistent negative emotions'). Themes were then reviewed and refined. Pseudonyms were used for the presentation of findings .

\section{Results}

From the analysis, both negative and positive themes were evident in participants' narratives and captured the psychological impact of working with trauma survivors (see Table 2 for a summary of themes and sub-themes). These themes are outlined and discussed below.

\section{Experiences of vicarious trauma}

All participants in the study were repeatedly exposed to aversive details of traumatic events. From the participants' accounts, it was evident that they experienced disruptions in cognitive schemas characterised by cynical views of the world and others. They experienced sub-clinical symptoms of PTSD and their symptoms form part of the primary diagnostic criteria for PTSD (APA, 2013) including intrusive memories, persistent negative emotional states, and alterations in arousal and reactivity in relation to clients' trauma. They also experienced somatic reactions as a result of trauma work. These themes are described below.

\section{Disruptions in cognitive schemas}

Several of the participants in the study reported perceived shifts in their worldview, particularly their assumptions about living in a benevolent, safe and just world:

I have now come to realise how unfair life is...bad things happen to good people. I now have a tainted view of the world and I'm aware of that. (Jennifer, major trauma area: sexual trauma) 
Perceptions of the world as unsafe were also reflected in participants' increased awareness of personal vulnerability and their attempts to ensure the safety of loved ones:

Table 2: Summary of themes and sub-themes

\begin{tabular}{|c|c|c|}
\hline Theme & Sub-themes & Codes \\
\hline \multirow[t]{5}{*}{$\begin{array}{l}\text { Experiences of } \\
\text { vicarious trauma }\end{array}$} & Disruption in cognitive schema & $\begin{array}{l}\text { tainted world view; believing that life is unfair; feeling unsafe and } \\
\text { vulnerable; increased awareness of human capacity of cruelty; } \\
\text { increased mistrust }\end{array}$ \\
\hline & Recurrent intrusive memory & $\begin{array}{l}\text { recurrent and intrusive thoughts about clients' trauma; triggered } \\
\text { by reminders of client's trauma; nightmares with content similar to } \\
\text { clients' trauma }\end{array}$ \\
\hline & Persistent negative emotions & $\begin{array}{l}\text { sadness; anger; frustration, helplessness; helpless rage; } \\
\text { powerlessness; numbing }\end{array}$ \\
\hline & Alterations in arousal and reactivity & $\begin{array}{l}\text { feeling irritable after work; inability to control anger, sleep } \\
\text { disturbances }\end{array}$ \\
\hline & Somatic symptoms & physical exhaustion; headaches; migraines; sore and tense muscles \\
\hline $\begin{array}{l}\text { Positive } \\
\text { transformations }\end{array}$ & Vicarious post-traumatic growth & $\begin{array}{l}\text { sense of optimism; awareness of personal strength in difficult } \\
\text { situations; ongoing sense of personal growth; feeling hopeful; } \\
\text { increased appreciation of ordinary connections }\end{array}$ \\
\hline
\end{tabular}

If I see a young girl who's been raped, I will definitely say to my daughter, 'just remember when you go on dates, men might do things, don't take a drink from them that is open'. So some of the stuff that I'm getting in the session I'm definitely feeding to her. (Jennifer)

I will sometimes say to my kids, 'you need to keep yourselves safe', because of this or that has happened...So yeah, I do actually carry certain clients more than [I] want to. (Monica, major trauma area: motor vehicle accidents, bereavement, physical and emotional abuse)

Furthermore, the sense of not being safe was evident in relational terms in that participants reported that they had become more 'aware of people's capacity for cruelty'. This led to an increased mistrust of others. This was most evident for female participants who worked with survivors of sexual trauma:

I remember when I was working at rape crisis centre, at one stage I was thinking all men are rapist and I was just really terrified of men in general...I suppose my worldview now is that men are potential perpetrators, doesn't mean that they all are, but there's a potential. (Jennifer)

\section{Recurrent, intrusive memories of client's trauma material}

Several participants reported involuntary and unwanted intrusive re-experiencing of their clients' trauma material. For example, Monica, who predominantly worked with survivors of interpersonal violence, reported experiencing recurrent and intrusive thoughts of the trauma survivors that she worked with:

Some clients actually stay with me. So there have been instances when I am trying to go to sleep at night and they are actually in my thoughts. 
Monica also reported experiencing triggering in response to reminders of the trauma: 'I am triggered when I see specific things, for instance on TV, then I have that fleeting feeling that reminds me of their trauma'.

For other participants, intrusions took the form of changes in the content of their dreams. Wendy, for example, reported that 'the nature of [her] dreams has changed' as a result of her work with survivors of sexual, physical and emotional abuse and that the content of the dreams [was] more intense'. Eugene, who worked with refugees escaping political violence and torture, reported frequent distressing nightmares:

I have dreams about violations, about being attacked, being chased.

Similarly, Jennifer, who predominantly worked with survivors of rape, mentioned that she experienced intrusive nightmares involving rape:

I sometimes dream about rape in different ways. Myself in it, my daughter in it...It's just very distressing dreams, very distressing.

\section{Persistent negative emotions}

Participants in the study reported an array of emotional responses as a result of engaging empathically with traumatised clients and some of these responses tended to persist for weeks or months after they had seen a particular client. Dominant emotional reactions included irritability, sadness, anger, frustration and feelings of helplessness and powerlessness. Participants also reported a feeling of 'helpless rage' involving anger at the violations certain clients experienced, coupled with a sense of helplessness/ powerlessness about making a meaningful change:

I feel a helpless rage...the anger comes from the fact that you know you try your best to help but in the South African context, there's lots of violence, lots of suffering...you can only do so much and I think that is where the anger comes from for me. (Monica)

I feel righteous anger quite a lot...in trying to figure out what to do about a situation where it is clear cut...there simply shouldn't be trauma against children. (Eugene)

One participant (Wendy) reported a sense of detachment as a result of repeated exposure to interpersonal trauma. She no longer experienced 'shock' or 'horror' in response to the client's story: 'nothing shocks me anymore, clients' traumas don't surprise me, I don't feel shocked anymore'.

\section{Alterations in arousal and reactivity}

Several participants reported that they experienced alterations in arousal and reactivity as a result of repeated engagement with trauma work. This included feeling irritable, experiencing outbursts of anger, sleep disturbances and hyper-vigilance . Eugene, for 
example, reported that prior to working with trauma he did not have a 'low tolerance level' but now has a 'very short fuse' and is 'quick to anger'. He also reported difficulty sleeping and attributed it to 'not processing the internalised trauma'. Other participants spoke of increased feelings of irritability, as evident in Kevin's account (major trauma area: violent crimes, domestic violence):

[I] go home or somebody says something to me that irritates me even if it's something normal, everyday things...then I know I have to take a few steps back because why suddenly do I want to take it out on someone...what they are doing or saying shouldn't have this response from me.

\section{Somatic symptoms}

Somatic symptoms refer to the physical complaints associated with a range of medical conditions or immune-mediated conditions connected with PTSD (Gupta, 2013) . All participants in the study reported somatic complaints that they attributed to the impact of their prolonged engagement in the field of trauma, as described by Kevin: If you listen attentively to a client's trauma, you inevitably pick some of those things up...you feel it in your body . . . it sits there somewhere in the body. Kevin also reported a sense of physical exhaustion due to repeated exposure to clients' trauma material. Eugene and Jennifer reported experiencing headaches, migraines, sore muscles and tension in the neck and shoulders, and they believed that these symptoms were work related. Wendy reported that she had recovered from asthma, but during her work with trauma survivors her asthma returned and she developed migraines.

\section{Positive transformations}

In the process of re-building the assumptive world after a traumatic experience, individuals may re-examine many aspects in their lives. Meaning making after trauma involves a consideration of the possible lessons and benefits of having survived a trauma (Kaminer \& Eagle, 2010). Given the evidence for such positive changes experienced directly by trauma survivors, it is expected that those who work with trauma survivors will experience transformations emblematic of vicarious post-traumatic growth. In the study, participants acknowledged their growth in the work of trauma. Their narratives included a greater appreciation for their lives and relationships as well as a renewed sense of personal strength and resilience.

\section{Vicarious post-traumatic growth}

All participants reported changes in one or more of the domains of growth outlined by Tedeschi and Calhoun (1996), including changes in philosophy of life, improved interpersonal relationships and changes in self-perception. Several participants reported that bearing witness to the ability of others to overcome traumatic events led to the experience of a greater sense of optimism and hope in relation to their own lives. Monica, for example, reported that she felt better able to cope with adversity in her own life because witnessing the resilience of others had made her more aware of her strength: 
As you go alone, you grow, and you change constantly...working with clients changes your worldviews...I learnt about how the most broken had the greatest capacity to give and to feel and to share and...I've come to realise that there is always hope, no matter how difficult things may seem...I sometimes do lose hope but only for brief moments and then I look at the things that are working for me rather than what's not working.

Participants also reported that working with trauma survivors has led to them appreciating interpersonal relationships with others. As evident in Eugene and Kevin's narratives:

I think the thing trauma work has done is to make me value connections much more, ordinary connections. (Eugene)

You see a client that goes through domestic violence...you are continuously reminded of those kind of things and then you realise...in terms of your own family, your own relationships, how important it is for you to work on those kind of things. (Kevin)

\section{Discussion}

The study found that the experience for therapists of working with trauma survivors is complex. For the participants in the study, trauma work evoked psychological distress as a result of its impact on pre-existing cognitive schemas. This corresponds with the findings in the existing literature (e.g. Farrenkopf, 1992; Rosenbloom, Pratt, \& Pearlman, 1995; Rich, 1997; Steed \& Downing, 1998; Canfield, 2005). Several participants reported an increasing sense of suspiciousness and distrust towards others. This was particularly the case with female therapists who worked with survivors of rape. These participants reported heightened mistrust of men and increased concerns about their own safety as well as the safety of significant others. For example, Jennifer reported that after working predominantly with survivors of rape, she began to consider all men as potential rapists and was concerned for her own safety and that of her daughter. Therapists' concerns and reactions aimed at keeping themselves and loved ones safe from harm have been documented in the literature (e.g. Chrestman, 1999; Iliffe \& Steed, 2000). These changes can be construed as disruptions in cognitive schemas as a result of vicarious traumatisation (McCann \& Pearlman, 1990).

In line with the existing literature (e .g . Pearlman \& MacIan, 1995; Schauben \& Frazier, 1995; Kassam-Adams, 1999; Meldrum, King, \& Spooner, 2002; Morrison, 2007), symptoms characteristic of PTSD were evident in participants' reports including intrusive re-experiencing of the client's trauma material in the form of nightmares and unwanted intrusive thoughts. These reactions can be reflective of insufficient integration of the client's trauma material on the part of the therapist (McCann \& Pearlman, 1990). Participants' responses to the trauma material presented by clients was also affective and included feelings of anger, sadness, helplessness and frustration. In common with the literature (e.g. Miller, 2001; Leach, 2008), anger and frustration were largely expressed in global statements regarding the injustice in the world and inhumanity. In addition, some participants in the study reported experiencing a sense of being emotionally detached from the trauma material presented by their clients. This type of response has been 
conceptualised as a form of emotional distancing or numbing in response to overwhelming emotional material or feelings of vulnerability evoked by aversive trauma narratives (Collins \& Long, 2003) . It is typically associated with emotional exhaustion and has been extensively documented in the literature on burnout (e.g. Hardiman \& Simmonds, 2013; Du Plessis et al., 2014; Tijdink, Vergouwen, \& Smulders, 2014). This type of emotional exhaustion occurs when a therapist's emotional resources become depleted by the chronic needs, demands, and expectations of their clients (Maslach, Schaufeli, \& Leiter, 2001).

Participants also reported experiencing somatic symptoms in the form of exhaustion, headaches, migraines as well as tension in their neck and shoulders as a result of trauma work . Similar somatic reactions have been found in therapists who worked with survivors or domestic violence and sexual violence (Iliffe \& Steed, 2000; Sommer \& Cox, 2006). Somatic complaints are common among survivors of trauma, particularly those who have suffered multiple and prolonged exposure to traumatic events (e .g . survivors of repeated childhood sexual abuse or political detainment and torture). Exposure to repeated trauma is thought to impact on physiological stress responses in that survivors tend to display significant conditioned autonomic reactions (e .g. increased heart rate and high blood pressure). Over time, this can result in somatic complaints including gastro-intestinal problems, migraines and physical pain (Van der Kolk, 1994; Courtois \& Ford, 2009). Somatic complaints have also been noted among those who work with survivors of trauma and it is hypothesised that the same mechanisms are involved in the manifestation of these symptoms (McFarlane, 2010).

Despite the adverse consequences, trauma work was reported to be rewarding and led to participants reporting experiences characteristic of vicarious post-traumatic growth . This included a renewed appreciation for life, a greater sense of personal strength, changed priorities and more meaningful interpersonal connections. Little is known about the process of psychological growth that can follow vicarious exposure to trauma (Arnold et al ., 2005; Barrington \& Shakespeare-Finch, 2013). However, the participants' descriptions of the rewarding nature of their work as well as their increased sense of hope and optimism is consistent with the emerging literature on this phenomenon (e .g . Arnold et al ., 2005; Splevins, Cohen, Joseph, Murray, \& Bowley, 2010; Hyatt-Burkhart, 2014).

\section{Conclusion}

The findings of this study have implications for psychologists who work with trauma survivors. It is evident that prolonged exposure to the trauma material presented by clients has significant psychological consequences for therapists in that it can lead to symptoms of vicarious trauma. However, working with trauma survivors does not only entail negative reactions. Trauma work can provide a vicariously rewarding experience as it allows the psychologists to witness growth and resilience. It is important to note that the reactions associated with vicarious traumatisation should be normalised and understood as a natural and inevitable consequence of working with challenging populations. Trauma practitioners should be aware of the signs of vicarious trauma and utilise effective coping strategies to ameliorate such impact. We recommend including content on vicarious 
trauma in training programmes so as to sensitise new therapists to the implications of working within the field of trauma.

\section{Acknowledgement}

The financial assistance of the National Research Foundation (NRF) towards this research is hereby acknowledged. Opinions expressed, and conclusions arrived at, are those of the authors and are not necessarily to be attributed to the NRF. The authors declare no competing and/or relevant financial interest which might be potential sources of bias or constitute conflict of interest.

\section{Endnote}

1 In this study, the term 'therapist(s)' refers to clinical or counselling psychologists. It has been used interchangeably with 'psychologist(s)' throughout the article. 


\section{References}

American Psychiatric Association (APA) . (2013). Diagnostic and statistical manual of mental disorders (5th edn). Washington, DC: Author .

Arnold, D., Calhoun, L. G., Tedeschi, R., \& Cann, A. (2005). Vicarious post-traumatic growth in psychotherapy . Journal of Humanistic Psychology, 45(2), 239-263 . http://dx .doi . org/10 .1177/0022167805274729

Atwoli, L., Stein, D. J., Williams, D. R., Mclaughlin, K.A., Petukhova, M., Kessler, R. C ., \& Koenen, K. C.(2013). Trauma and post-traumatic stress disorder in South Africa: Analysis from the South African Stress and Health Study . BMC Psychiatry, 13(1), 112 . http://dx .doi .org/10 .1186/1471-244X-13-182

Barrington, A . J ., \& Shakespeare-Finch, J . (2013) . Working with refugee survivors of torture and trauma: An opportunity for vicarious post-traumatic growth . Counselling Psychology Quarterly, 26(1), 89-105 . http://dx .doi .org/10 .1080/095150 70 .2012 .727553

Braun, V ., \& Clarke, V . (2006). Using thematic analysis in psychology . Qualitative Research in Psychology, 3(2), 77-101 . http://dx .doi .org/10 .1191/1478088706qpo630a

Calhoun, L . G ., \& Tedeschi, R. G . (2006). The foundations of posttraumatic growth: An expanded framework. In L.G.Calhoun \& R. G. Tedeschi (eds), Handbook of posttraumatic growth: Research and practice (pp . 1-23). Mahwah: Erlbaum .

Canfield, J. (2005). Secondary traumatization, burnout, and vicarious traumatization . Smith College Studies in Social Work, 75(2), 81-101 . http://dx .doi .org/10 .1300/ J497v75no2_06

Chrestman, K . (1999). Secondary exposure to trauma and self-reported distress among therapists . In B . H . Stamm (ed .), Secondary traumatic stress: Self-care issues for clinicians, researchers, and educators (2nd edn, pp . 29-36) . Lutherville: Sidran Press .

Collins, S ., \& Long, A . (2003) . Too tired to care? The psychological effects of working with trauma . Journal of Psychiatric and Mental Health Nursing, 1O(1), 17-27 . http:// dx .doi .org/10.1046/j.1365-2850.2003.00526.x

Courtois, C . A ., \& Ford, J . D . (eds) . (2009) . Treating complex traumatic stress disorders: An evidence-based guide. New York: The Guilford Press .

Du Plessis, T., Visagie, S ., \& Mji, G. (2014). The prevalence of burnout amongst therapists working in private physical rehabilitation centres in South Africa: A descriptive study . South African Journal of Occupational Therapy, 44(2), 11-16.

Edwards, D . J . A . (2009) . Treating post-traumatic stress disorder in South Africa: An integrative model grounded in case-based research . Journal of Psychology in Africa, 19(2), 189-198.

Ehlers, A., \& Clark, D . M . (2000). A cognitive model of posttraumatic stress disorder . Behaviour Research and Therapy, 38(4), 319-345 . http://dx .doi .org/10 .1016/ Soo057967(99)00123-0

Farrenkopf, T . (1992). What happens to therapists who work with sex offenders . Journal of Offender Rehabilitation, 18(3-4), 217-224 . http://dx .doi .org/10.1300/Jo76v18no3_16

Figley, C . R . (1995). Systemic traumatisation: Secondary traumatic stress disorder in family therapists . In R. Mikesell, D . Lusterman, \& S . McDaniel (eds), Integrating family therapy: 
Handbook of family psychology and systems theory (pp . 571-581). Washington, DC: American Psychology Association . http://dx .doi .org/10 .1037/10172-033

Figley, C . R. (1999). Compassion fatigue: Towards a new understanding of the costs of caring . In B . H. Stamm (Ed .), Secondary traumatic stress: Self-care issues for clinicians, researchers, \& educators (2nd edn, pp . 3-28). Lutherville: Sidran Press .

Finlay, L. (2009) . Debating phenomenological research methods. Phenomenology \& Practice, $3(1), 6-25$.

Gupta, M . A . (2013). Review of somatic symptoms inpost-traumatic stress disorder . International Review of Psychiatry (Abingdon, England), 25(1), 86-99 . http://dx .doi . org/10 .3109/09540261.2012 .736367

Hardiman, P ., \& Simmonds, J . G . (2013) . Spiritual well-being, burnout and trauma in counsellors and psychotherapists . Mental Health, Religion \& Culture, 16(10), 10441055.http://dx .doi .org/10.1080/13674676 .2012 .732560

Herman, J . L . (1992) . Trauma and Recovery: The Aftermath of Violence - from Domestic Abuse to Political Terror. New York: Basic Books .

Hyatt-Burkhart, D. (2014). The experience of vicarious post-traumatic growth in mental health workers. Journal of Loss and Trauma, 19(5), 452-461. http://dx.doi.org/10.1080/15325024.2013.797268

Iliffe, G ., \& Steed, L . (2000) . Exploring the counsellor's experience of working with perpetrators and survivors of domestic violence. Journal of Interpersonal Violence, 15(4), 393-412 . http://dx.doi.org/10.1177/088626000015004004

Janoff-Bulman, R. (1985). The aftermath of victimization: Rebuilding shattered assumptions. Trauma and Its Wake: The Study and Treatment of Post-Traumatic Stress Disorder. New York: Brunner/Mazel.

Jordaan, I., Spangenberg, J. J ., Watson, M . B ., \& Fouchè, P . (2007). Emotional stress and coping strategies in South African clinical and counselling psychologists. South African Journal of Psychology: Intergroup Contact: Special Issue, 37(4), 835-855 . http://dx.doi.org/10.1177/008124630703700411

Kaminer, D ., \& Eagle, G. (2010) . Traumatic stress in South Africa . Johannesburg: Wits University Press .

Kaminer, D ., Grimsrud, A ., Myer, L ., Stein, D ., \& Williams, D . (2008) . Risk for posttraumatic stress disorder associated with different forms of interpersonal violence in South Africa . Social Science \& Medicine, 67(10), 1589-1595 . http://dx .doi .org/10 $.1016 / \mathrm{j}$.socscimed .2008 .07 .023

Kassam-Adams, N. (1999). The risks of treating sexual trauma: Stress and secondary trauma in psychotherapists. In B. H. Stamm (Ed .), Secondary traumatic stress: Self care issues for clinicians, researchers and educators (2nd edn, pp . 37-47). Lutherville: Sidran Press.

Leach, C. W . (2008) . Envy, inferiority, and injustice: Three bases of anger about inequality. New York: Oxford University Press .

Ludick, M ., Alexander, D ., \& Carmichael, T . (2007) . Vicarious traumatisation: Secondary traumatic stress levels in claims workers in the short-term insurance industry in South Africa.Problems and Perspectives in Management, 5(3), 99-110 . 
MacRitchie, V ., \& Leibowitz, S . (2010) . Secondary traumatic stress, level of exposure, empathy and social support in trauma workers. South African Journal of Psychology. SuidAfrikaanse Tydskrif vir Sielkunde, 4O(2), 149-158 . http://dx .doi .org/10 $.1177 / 008124631004000204$

Maslach, C . (1982) . Understanding burnout: Definitional issues in analyzing a complex phenomenon. In W. S. Paine (ed .), Job stress and burnout: Research, theory and intervention perspectives (pp . 29-40). Beverly Hills: Sage Publications .

Maslach, C., Schaufeli, W . B ., \& Leiter, M . P . (2001). Job burnout. Annual Review of Psychology, 52(1), 397-422 .http://dx .doi .org/10 .1146/annurev .psych .52 .1 .397

McCann, I . L ., \& Pearlman, L. A . (1990). Vicarious traumatization: A framework for understanding the psychological effects of working with victims . Journal of Traumatic Stress, 3(1), 131-149. http://dx .doi .org/10 .1007/ BFoo975140

McFarlane, A . C . (2010). The long-term costs of traumatic stress: Intertwined physical and psychological consequences . World Psychiatry; Official Journal of the World Psychiatric Association (WPA), 9(1), 3-10 . http://dx .doi . org/10 .1002/j .2051-5545 .2010 .tboo254.x

Mcphail, J . C . (1995). Phenomenology as Philosophy and Method: Applications to ways of doing special education. Remedial and Special Education, 16(3), 159-165 . http:// dx .doi .org/10 .1177/074193259501600305

Meldrum, L ., King, R ., \& Spooner, D . (2002) . Secondary traumatic stress in case managers working in community mental health services. In C. R . Figley (ed .), Treating compassion fatigue (pp. 85-106) . New York: Brunner-Routledge .

Miller, D . T . (2001). Disrespect and the experience of injustice. Annual Review of Psychology, 52(1), 527-553 . http://dx .doi .org/10 .1146/annurev .psych .52 .1.527

Morrison, Z . (2007) . 'Feeling heavy': Vicarious trauma and other issues facing those who work in the sexual assault field.Australian Institute of Family Studies, 4, 1-19.

Padmanabhanunni, A ., \& Edwards, D. J. A. (2015). Rape survivors' experiences of the Silent Protest: Implications for promoting healing and resilience. Qualitative Health Research. Published online: http://dx.doi.org/10 .1177/1049732315573201

Pearlman, L . A ., \& Caringi, J . (2009) . Living and working self-reflectively to address vicarious trauma. In C. A . Courtois \& J . D . Ford (eds), Treating complex traumatic stress disorders: An evidence-based guide (pp. 202-224). New York: Guilford Press .

Pearlman, L.A., \& MacIan, P.S. (1995). Vicarious traumatization: An empirical study of the effects of trauma work on trauma therapists. Professional Psychology, Research and Practice, 26(6), 558-565. http://dx .doi .org/10.1037/0735-7028.26.6.558

Pearlman, L. A ., \& Saakvitne, K. W . (1995). Trauma and the therapist: Countertransferance and vicarious traumatization in psychotherapy with incest survivors. New York: Norton .

Rich, K. D . (1997). Vicarious traumatization: A preliminary study . In S . B . Edmunds (ed .), Impact: Working with sexual abusers (pp . 75-88). Brandon: Safer Society Press .

Rosenbloom, D . J ., Pratt, A. C., \& Pearlman, L. A . (1995). Helpers' responses to trauma work: Understanding and intervening in an organization. In B . H . Stamm (ed .), Secondary traumatic stress: Self-care issues for clinicians, researchers, and educators (pp.65-79). Baltimore: Sidran Institute Press . 
Schauben, L. J ., \& Frazier, P. A . (1995). Vicarious trauma: The effects on female counselors of working with sexual violence survivors . Psychology of Women Quarterly, 19(1), 49-64 . http://dx.doi.org/10.1111/j.1471-6402.1995.tbo0278.x

Sommer, C., \& Cox, J. (2006). Sexual violence counselors' reflections on supervision: Using stories to mitigate vicarious traumatization. Journal of Poetry Therapy, 19(1), 3-16. http://dx.doi.org/10.1080/08893670600565587

Splevins, K. A ., Cohen, K ., Joseph, S ., Murray, C ., \& Bowley, J . (2010) . Vicarious posttraumatic growth among interpreters. Qualitative Health Research, 20(12), 1705-1716. http://dx.doi.org/10.1177/1049732310377457

Steed, L. G ., \& Downing, R . (1998). A phenomenological study of vicarious traumatisation amongst psychologists and professional counsellors working in the field of sexual abuse/assault . Australasian Journal of Disaster and Trauma Studies, 2 . Retrieved on 14 March 2015 from http://www . massey .ac .nz/ trauma/issues/1998-2/steed.

Tedeschi, R . G ., \& Calhoun, L . G . (1996). The posttraumatic growth inventory: Measuring the positive legacy of trauma . Journal of Traumatic Stress, 9(3), 455-471 . http://dx.doi.org/10.1002/jts.2490090305

Tijdink, J . K., Vergouwen, A . M ., \& Smulders, Y. M . (2014). Emotional exhaustion and burnout among medical professors; a nationwide survey . BMC Medical Education, 14(1), 183. http://dx .doi .org/10.1186/1472-6920-14-183

Van der Kolk, B. (1994). The body keeps the score: Memory and the evolving psychobiology of posttraumatic stress . Harvard Review of Psychiatry, 1(5), 253-265 . http://dx.doi.org/10.3109/10673229409017088 